\title{
PERANAN JABATAN AGAMA ISLAM DAN AGENSI KERAJAAN DI NEGERI JOHOR DALAM MEMELIHARA KEDUDUKAN AGAMA ISLAM SEWAKTU PEMODENAN JOHOR, 1862-1941
}

\author{
Muhammad Izuan Abdul Rahman
}

\begin{abstract}
The term of 'modernization' often brings negative perceptions especially in the context of tradition and religion. Transformation and reformation during a period of the modernization are often the main reasons for the erosion of tradition and religion in a society. However, this did not happen at the time of Johor's modernization. Instead, modernization brought positive effects on the growth of Islam in Johor. Undeniably, there were many problems which arose from this modernization despite the Johor's government firm actions to keep Islam safe from the modernization process. This can be seen through the role played by Jabatan Agama Islam and several government's agencies in neutralizing the effects of modernization upon Islam in Johor. This study focuses on the roles and actions that were taken by the government's agencies in Johor to maintain the position of Islam at the time of Johor's modernization from 1862 until 1941.
\end{abstract}

\section{Pengenalan}

Asakan arus imperialisme yang menyerang Johor memaksa pemerintah Johor, Maharaja Abu Bakar, melancarkan reformasi pentadbiran untuk merekonstruksi semula pentadbiran kerajaan Johor. Hal ini seterusnya 
menjadikan Johor sebagai sebuah negeri Melayu yang termoden berbanding negeri Melayu yang lain. Walau bagaimanapun, proses pemodenan ini secara tidak langsung telah memberikan impak negatif terhadap perjalanan agama Islam di negeri Johor seperti gejala tidak berpuasa di bulan Ramadan dan ponteng solat Jumaat, penularan maksiat serta masalah ajaran sesat dan perbuatan syirik.

Rentetan daripada cabaran tersebut, pemerintah Johor telah mengambil inisiatif menggubal fasal 57 Undang-undang Tubuh Kerajaan Johor tahun 1895 yang secara tidak langsung telah mengangkat agama Islam menjadi agama rasmi kerajaan Johor. Selain itu, bagi memastikan perjalanan pentadbiran dan pengurusan hal ehwal agama Islam berjalan lancar, kerajaan Johor telah menggabungkan Jabatan Agama dan Pelajaran sebagai satu institusi.

Walau bagaimanapun, tanggungjawab mengawal selia hal ehwal agama Islam tidak hanya dibebankan di bahu Jabatan Agama islam dan agensi pelaksana di bawahnya seperti Pejabat Mufti, Pejabat Kadi Besar dan Pemeriksa Hal-hal Agama yang membantu gerak kerja Jabatan Agama Islam. Sebaliknya, usaha tersebut dijalankan secara kolektif dengan kerjasama daripada beberapa agensi kerajaan di negeri Johor seperti Pejabat Daerah, pihak Polis serta Penghulu dan Imam yang tidak berat tulang untuk membantu Jabatan Agama Islam untuk memelihara dan memulihara kedudukan agama Islam di negeri Johor sewaktu proses pemodenan Johor. Hal ini dapat dilihat berdasarkan peranan dan langkah-langkah yang telah diambil oleh Jabatan Agama Islam Johor dan agensi kerajaan yang terlibat dalam memelihara dan memulihara agama Islam di Johor sepanjang tempoh 1862 hingga 1941.

\section{Jabatan Agama Islam Negeri Johor: Satu Tinjauan Retrospektif}

Seperti yang telah dihuraikan di atas, Jabatan Agama dan Pelajaran telah ditubuhkan secara rasminya pada tahun 1895 dengan Engku Muhd Khalid sebagai Yang Dipertua Jabatan Agama dan Pelajaran yang pertama. ${ }^{1}$ Namun, pada tahun 1906 jabatan ini dirombak dengan portfolio berkenaan pelajaran telah diasingkan dengan penubuhan Jabatan Pelajaran yang bergerak sebagai satu komponen berasingan daripada Jabatan Agama. ${ }^{2}$ Semenjak itu, Jabatan Agama dan Pelajaran dikenali sebagai Jabatan Agama Islam Negeri Johor. Tugas utama Jabatan Agama Islam ialah menjalankan kerja-kerja berkaitan perkara yang melibatkan agama negeri dan sekalian orang Islam. ${ }^{3}$

Dalam konteks ini, segala aspek pentadbiran dan pengurusan hal-ehwal agama Islam akan diselia oleh Pejabat Agama di Johor Bahru dan dibantu oleh beberapa cawangan Pejabat Agama yang didirikan 
di setiap daerah. Tertakluk di bawah Jabatan Agama Islam, terdapat beberapa agensi pelaksana lain yang mempunyai bidang tugas tertentu seperti Pejabat Mufti, Pejabat Kadi Besar dan Pemeriksa Hal-hal Agama yang membantu gerak kerja Jabatan Agama Islam.

Dalam konteks yang menyeluruh, Pejabat Mufti telah ditetapkan sebagai sebuah agensi yang berperanan dalam menjalankan kerja-kerja berkenaan fatwa dan menyelesaikan masalah hukum syarie manakala pejabat Kadi pula berperanan mengendalikan urusan berkenaan Mahkamah Kadi Syariah, mendaftarkan nikah cerai dan rujuk serta mengelolakan kutipan zakat. Selain itu, bagi tugas Pemeriksa Hal-hal agama pula, telah ditetapkan bahawa agensi ini berperanan sebagai pemantau segala bentuk perjalanan dan perkembangan agama Islam di negeri Johor.

\section{Peranan Jabatan Agama Islam dalam Meneutralkan Kesan Pemodenan Johor}

Menyedari kesan daripada proses pemodenan yang dianggap mampu mengancam agama Islam, Jabatan Agama Islam mula memainkan peranan yang proaktif dalam memelihara dan memulihara kedudukan agama Islam di negeri Johor. Pada peringkat awal proses pemodenan, cabaran utama yang dihadapi oleh agama Islam adalah serangan pengaruh sekular Barat khususnya dalam bidang perundangan yang secara langsung mampu menghakis nilai-nilai Islam dalam kehidupan seharian. ${ }^{4}$

Sehubungan itu, Jabatan Agama Islam telah mengambil inisiatif untuk menggubal beberapa undang-undang khas untuk umat Islam sebagai alternatif bagi menggantikan hukum syarak yang menjadi "kambing hitam" proses pemodenan. Dalam konteks kajian ini, fokus akan diberikan kepada perlaksanaan Undang-undang Mal Islam "Majalah Ahkam" sekitar 1913 dan Undang-undang Kesalahan-kesalahan Orang Islam 1919.

Undang-undang Mal Islam "Majalah Ahkam" ialah satu set undangundang yang menjadi garis panduan bagi umat Islam di Johor dalam kehidupan seharian. Undang-undang ini merangkumi segala kegiatan seharian seperti urusan jual beli, pinjam-meminjam, hutang, gadaian, amanah, rampasan dan penyitaan serta pelbagai aspek yang berkaitan dengan aktiviti sehari-hari. ${ }^{5}$ Dalam konteks negeri Johor, Majalah Ahkam telah diangkat menjadi rujukan utama di mahkamah dalam menyelesaikan masalah-masalah yang dihadapi oleh rakyat seperti yang terkandung di dalam pendahuluan Majalah Ahkam:

Bahawasanya dengan persetujuan pegawai-pegawai yang terutama bagi Jabatan Agama dan berkenaannya dan setelah disahkan 
terjemahannya maka di persembahkan kepada maklum ke bawah Duli Yang Maha Mulia Ibrahim Sultan Yang Dipertuan Johor dipohonkan kebenaran supaya di cap (dicetak) oleh kerajaan ditetapkan dipakai menjadi sebuah daripada kitab-kitab panduan berkenaan dengan hukum-hukum syar-ie (menurut bagaimana kecualiannya yang disebutkan dalam Undang-undang Tubuh Kerajaan Johor fasal yang ke 49). ${ }^{6}$

Pelaksanaan Undang-undang Mal Islam "Majalah Ahkam" secara tidak langsung mencerminkan gaya hidup dan aktiviti kehidupan seharian umat Islam di Johor adalah berlandaskan hukum syarak. Ini bermakna agama Islam masih terus menjadi teras kehidupan seharian walaupun pelbagai teknik dan sistem pentadbiran barat yang bersifat sekular diaplikasikan di negeri Johor. Selain itu, penelitian terhadap genesis Undang-undang Mal Islam "Majalah Ahkam" mendapati bahawa undangundang ini ialah undang-undang yang diguna pakai oleh Kerajaan Turki Uthmaniyah. ${ }^{7}$

Pelaksanaan undang-undang ini berkait rapat dengan hubungan diplomatik antara kerajaan Johor dengan Kerajaan Turki Uthmaniyah sejak zaman Maharaja Abu Bakar. ${ }^{8}$ Hal ini secara tidak langsung mencerminkan peranan yang dimainkan oleh Jabatan Agama Islam Johor yang sentiasa mengemaskini sistem pentadbiran dan perundangannya untuk memajukan agama Islam. Oleh itu, Jabatan Agama Islam telah mengimport dan mengaplikasikan nilai-nilai Islam yang moden dari negara-negara Arab. ${ }^{9}$ Malahan dalam konteks agama, Johor dilihat menjadikan negara-negara Arab sebagai model untuk membangun dan mengembangkan ajaran Islam. Malahan, Sultan Ibrahim sendiri pernah mengarahkan Yang Dipertua Agama Islam Johor untuk pergi ke Mesir selama enam bulan pada 1937 bagi meninjau dan meneliti undang-undang Islam di Mesir. ${ }^{10} \mathrm{Hal}$ ini menggambarkan bahawa perkembangan agama Islam berjalan selari dengan proses pemodenan di Johor.

Hujah Rahimah Abd. Aziz yang mengatakan bahawa pelaksanaan "Panel Code"11 dan "Civil Code" pada 1910 sebagai bukti kemerosotan agama Islam di Johor adalah satu pandangan yang bersifat pesimisme. ${ }^{12}$ Hal ini kerana Jabatan Agama Islam Johor telah melancarkan "counter attack" dengan menggubal Undang-undang Kesalahan-kesalahan Orangorang Islam 1919. ${ }^{13}$ Perlu ditegaskan dalam perbincangan ini bahawa undang-undang yang diwartakan pada 18 November 1919 ini hanya dikuatkuasakan ke atas orang Islam sahaja. Objektif utama penggubalan undang-undang ini adalah untuk memelihara akidah umat Islam, memerangi gejala pelacuran, zina dan sumbang mahram. ${ }^{14}$ Contohnya 
dalam konteks masalah pelacuran, fasal ke-4 undang-undang ini memperuntukkan:

Any woman who leads an in an immoral life by becoming a prostitute or co-habiting with a man to whom she is not married shall be guilty of an offence and for each first offence such offence shall be liable on conviction to simple imprisonment for term not exceeding one month and for each subsequent such off offence to simple imprisonment for a term not exceeding three month. ${ }^{15}$

Perlu ditegaskan dalam perbincangan ini bahawa undang-undang yang digagaskan oleh Jabatan Agama Islam ini bukan sekadar retorik semata-mata. Ini kerana, berdasarkan penelitian terhadap Fail Pejabat Agama, Fail Pejabat Kadi Besar dan Fail General Adviser mendapati terdapat rekod-rekod yang membuktikan perlaksanaan undang-undang ini di Johor. Contohnya, surat Kassim bin Idris kepada Tuan General Adviser Johor yang menyatakan bahawa:

... setelah keluar undang-undang itu banyak kali perempuanperempuan Melayu telah di tangkap dan didakwa oleh polis atau dengan bawaan dari Religious Department (Pejabat Agama), banyaklah daripada mereka-mereka itu dihukum oleh majistret ${ }^{16}$

Ironinya, Undang-undang Kesalahan-kesalahan Orang-orang Islam 1919 dilapisi oleh Undang-undang Memutuskan Masalah Perkara-perkara Hukuman Islam 1919 yang secara bertulis memberikan autoriti kepada Mufti untuk menyelesaikan sebarang polemik yang timbul berkaitan perlaksanaan Undang-undang Kesalahan-kesalahan Orang-orang Islam 1919. ${ }^{17}$ Fenomena ini dilihat sebagai tindakan yang menongkah arus kerana sistem politik tradisional Melayu meletakkan bahawa sultan ialah ketua agama yang mempunyai autoriti untuk menyelesaikan sebarang permasalahan agama. ${ }^{18}$

Di samping itu, Jabatan Agama Islam turut memainkan peranan penting dalam menyebarkan dakwah Islam sewaktu proses pemodenan. Oleh itu, adalah tidak menghairankan jika dalam tempoh tahun 1930-an terdapat ramai "saudara baru" yang memeluk agama Islam. Perkara ini mencerminkan keberkesanan peranan yang dimainkan oleh Jabatan Agama Islam dalam mengembangkan ajaran Islam. Dalam konteks ini, individu-individu yang baru memeluk agama Islam akan diberi bantuan dan sokongan baik dari segi material mahupun moral. Contohnya, Jabatan Agama Islam akan mengirimkan tenaga pengajar untuk membimbing dan memberikan tunjuk ajar ilmu agama kepada saudara baru. ${ }^{19}$ 
Pada masa yang sama, bantuan kewangan juga diberikan kepada saudara baru bagi membantu mereka menghadapi cabaran pada peringkat awal memeluk agama Islam. ${ }^{20}$ Ini kerana, "saudara baru" ini mungkin akan disisihkan oleh keluarga dan rakan-rakan sekali gus mengakibatkan mereka hilang tempat bergantung. Oleh yang demikian, bantuan kewangan dapat meringankan bebanan mereka. Dalam konteks negeri Johor, individu yang baharu sahaja memeluk agama Islam dikehendaki mempelajari asas-asas agama dan fardu ain selama sebulan penuh. Oleh itu, terdapat kebarangkalian mereka ini tidak boleh bekerja kerana perlu menghadiri kelas agama untuk mempelajari ilmu fardu ain seperti cara-cara berwuduk, mendirikan solat lima waktu, mandi wajib dan sebagainya. Perkara-perkara ini memakan masa yang agak lama serta memerlukan komitmen yang tinggi oleh saudara baru tersebut. Tambahan pula, untuk mempelajari ilmu fardu ain, bimbingan daripada tenaga pengajar khususnya dalam aspek amali amat diperlukan. Oleh itu, Jabatan Agama Islam melalui Pejabat Kadi Besar telah memperuntukkan wang baitulmal untuk menampung perbelanjaan makan dan minum mereka sewaktu dalam tempoh pembelajaran tersebut. ${ }^{21}$

\section{Pejabat Mufti Besar dan Pejabat Kadi Besar Johor}

Dalam usaha mengawal selia agama Islam, Yang Dipertua Agama Islam dibantu oleh seorang Mufti Kerajaan dan Kadi Besar. Jawatan Mufti dan Kadi Besar dipercayai telah wujud lebih awal daripada Jabatan Agama dan Pelajaran. ${ }^{22}$ Buktinya pada tahun 1873 Syed Salim bin Ahmad AlAttas telah dilantik sebagai Mufti Kerajaan manakala Imam Haji Abdul Rahman pula menyandang portfolio sebagai Kadi Besar Johor. ${ }^{23}$ Dalam konteks negeri Johor, Mufti dipertanggungjawabkan untuk:

... menjalankan kerja-kerja yang berkenaan dengan memberi fatwa atas semua masalah hukum syarak bagi tiap-tiap bahagian dalam Iktikad, Ibadat, Muamalat, Munakahat, Jenayat dan segala hukum far-ngi-yah cawangan-cawangannya ilmu agama Lu-grha-tul agama dan adabnya. ${ }^{24}$

Sehubungan itu, Mufti menjadi tempat rujukan sekiranya timbul sebarang polemik atau kekeliruan berkenaan agama Islam. Oleh itu, sebagai tempat rujukan asas Pejabat Mufti mula menjadi tumpuan orang ramai yang menghadapi kemusykilan mengenai hal ehwal agama Islam. Perkara ini dapat dilihat daripada laporan-laporan Tahunan Jabatan Agama Islam serta Fail Jabatan Agama Islam (Mufti Johor) yang memaparkan beberapa persoalan mengenai hal ehwal agama yang dirujuk kepada Mufti Johor. ${ }^{25}$ Pada masa yang sama, kepakaran Mufti 
dalam selok-belok ilmu agama secara tidak langsung menjadikannya individu yang bertanggungjawab untuk mengeluarkan tauliah bagi mengajar agama di negeri Johor. ${ }^{26}$

Pada masa yang sama, Mufti Besar Johor turun padang untuk menjelajah seluruh Johor bersama Yang Dipertua Agama untuk melihat sendiri perjalanan agama Islam di negeri Johor serta menyampaikan ceramah-ceramah agama di kawasan yang dilawatinya. ${ }^{27}$ Malahan, Mufti juga dilihat sering untuk menegur sebarang masalah agama dan cuba untuk mencari jalan penyelesaiannya. Contohnya, rentetan daripada gejala tidak bersembahyang Jumaat, Mufti Johor telah mencetuskan idea agar diwujudkan sebuah buku khas untuk ditandatangani oleh kakitangan kerajaan sebagai bukti kehadiran mereka menunaikan solat Jumaat. Kegagalan menandatangani buku kehadiran tersebut akan mengakibatkan seseorang itu dikira tidak hadir menunaikan solat Jumaat dan boleh dikenakan denda oleh Mahkamah Kadi. ${ }^{28}$ Selain itu juga, Mufti Johor pada tahun 1928 mencadangkan agar segala aktiviti jual beli dilarang pada hari Jumaat antara 12.30 tengah hari hingga 2.30 petang bagi mengelakkan gejala tidak sembahyang Jumaat. ${ }^{29}$

Selain itu, terdapat juga Kadi Besar Johor yang turut membantu Yang Dipertua Jabatan Agama. Skop tugas Kadi Besar ialah menjalankan kerja berkaitan dengan penguatkuasaan undang-undang Islam di Johor. Dalam konteks ini Kadi Besar tidak sekadar bertanggungjawab mentadbir Mahkamah Kadi Syariah malah turut berperanan sebagai hakim bagi Mahkamah Kadi Syariah. Segala urusan mengenai pendaftaran nikah-cerai dan rujuk, pembahagian harta pusaka, kutipan zakat, pengurusan harta baitulmal dan pentadbiran masjid juga tertakluk di bawah bidang kuasa Kadi Besar Johor.

Oleh kerana bidang tugas yang begitu kompleks, maka Kadi Besar dibantu oleh Penolong-penolong Kadi yang menjalankan tugastugas Kadi Besar di peringkat daerah manakala di peringkat kampung pula tugas Kadi Besar ini dijalankan oleh Naib Penolong Kadi. Selaku pihak yang bertanggungjawab menguruskan wang Baitulmal, pihak Pejabat Kadi Besar telah mengambil inisiatif untuk menggunakan wang Baitulmal bagi memberi pinjaman kepada kakitangan kerajaan yang ingin berkahwin. ${ }^{30} \mathrm{Hal}$ ini mempunyai hubung kait dengan masalah zina yang semakin meruncing di negeri Johor. Oleh itu, langkah menggalakkan perkahwinan ialah satu alternatif untuk membasmi gejala maksiat di Johor.

Perbincangan di atas secara tidak langsung menepis dakwaan bahawa proses pemodenan telah mengecilkan skop agama Islam di Johor. ${ }^{31}$ Walaupun secara kasarnya pengaruh golongan agama dan undang-undang Islam kelihatan seolah-olah merosot atau menurun namun hakikatnya hal ini tidak berlaku. Ini kerana, Jabatan Agama Islam 
telah menyediakan pelan alternatif dalam usaha untuk memelihara dan memulihara serta mengembangkan lagi agama Islam di Johor.

\section{Pemeriksa Hal-hal Agama}

Tugas untuk menjamin kelangsungan ajaran Islam dalam kehidupan seharian masyarakat merupakan satu tugas yang kompleks. Oleh yang demikian, Jabatan Agama Islam telah menubuhkan jawatan Pemeriksa Hal-hal Agama untuk menjadi "mata dan telinga" bagi Jabatan Agama Islam untuk memantau dan melaporkan sebarang komplikasi yang timbul terhadap perjalanan Agama Islam di Johor. Bidang tugas Pemeriksa Hal-hal Agama ialah menyiasat sebarang laporan atau kes kesalahan terhadap agama Islam seperti zina, ajaran sesat dan perbuatan syirik seperti yang terkandung dalam arahan yang dikeluarkan oleh Yang Dipertua Jabatan Agama Islam kepada Pemeriksa Hal Ehwal Agama:

Rentetan daripada kekerapan mendapat berita dari kampung ada hal agama yang tiada bagus dan ada juga pendengaran mengadakan ajaran atau sekolah agama lain-lain diadakan dalam kampung yang jauh dari bandar dan orang menyiarkan kitab-kitab yang menyalahi agama Islam dan pemujuk-pemujuk agama lain menjajah serata kampung suatu hal ini tiada pun dapat diketahui oleh Pemeriksa Hal Ehwal Agama yang ada dalam Johor ... dari sebab itu hendaklah dari tarikh ini hendaklah diperintahkan mereka-mereka itu pergi menyiasat dan mengambil tahu atas semua hal agama dalam kampung-kampung. ${ }^{32}$

Sehubungan itu, Pemeriksa Hal-hal Agama terpaksa menjelajah ke setiap pelosok negeri Johor khususnya di kampung-kampung dan kawasan pedalaman untuk memastikan perjalanan Agama Islam berjalan lancar di samping memantau pekerjaan imam dan Naib Penolong Kadi di kampung-kampung. Selain itu, Pemeriksa Hal-hal Agama perlu menulis laporan harian mengenai tugas-tugas yang telah dilaksanakan untuk diperiksa oleh Yang Dipertua Jabatan Agama Islam Johor pada setiap awal bulan seperti yang terkandung di dalam Penyata laporan Pemeriksa Hal-hal Agama Johor Baharu:

Pada pukul 9 pagi saya pergi bersama dengan kadi pergi ke rumah mahmud bertanyakan bertanyakan hal agama dalam Kuala Sedeli dan harta baitulmal dan zakat fitrah kemudian katanya dalam perkara agama sedang sahaja, harta baitulmal yang saya dapat tahu tiada dan zakat fitrah nampaknya ada lebih daripada taip tahun dari situ saya pergi ke rumah penghulu Akhil berjumpa kepadanya 
didapati kenyataan lebih kurang bagaimana kenyataan Mahmud itu juga. ${ }^{33}$

Melalui kaedah ini, secara tidak langsung Yang Dipertua Jabatan Agama Islam dapat mengetahui dan memantau perkembangan agama Islam di seluruh pelosok negeri Johor. Lantaran itu, Penyata Pemeriksa Hal-hal Agama merupakan satu sumber sejarah yang mencerminkan perjalanan dan perkembangan agama Islam di negeri Johor serta merupakan ajen penting dalam memerangi gejala ponteng puasa di bulan Ramadan. ${ }^{34}$ Ini kerana, Pemeriksa Agama diamanahkan untuk memeriksa kedaikedai makan yang dibuka pada waktu tengah hari bagi memastikan tiada orang Islam yang makan dan minum di kedai tersebut:

pukul 12 siang pergi ke bandar Johor memeriksa kedai-kedai makan berkenaan dengan orang yang tiada puasa didapati terjumpa orangorang makan di kedai 10 orang dari situ ke pejabat kadi Johor masuk aduan dan mintak keluarkan saman ${ }^{35}$

Pernyataan ini menceritakan kegiatan-kegiatan agama yang dilaksanakan dan masalah agama yang timbul secara terperinci. Contohnya, Haji Ahmad bin Omar seorang Pemeriksa Hal-hal Agama Johor menceritakan perihal penduduk kampung dan kegiatan agama di Tanjung Sedeli yang terletak dalam daerah Kota Tinggi Johor. Ini kerana, pada setiap minggu akan ada seorang “...bernama Ishak akan datang mengajar kepada penduduk-penduduk kampung ini dalam satu minggu empat hari orang yang belajar lelaki dan perempuan lebih kurang 20 orang dalam syarat rukun dan Fatihah dan Tahiyat."36

Dari segi prosedur tugas pula, Pemeriksa Hal-hal Agama pada peringkat awal perlu menjalankan siasatan terlebih dahulu dengan mendapatkan maklumat daripada masyarakat setempat untuk mengumpul bukti sebelum mengambil tindakan memeriksa sendiri ke tempat kes itu atau berjumpa dengan tertuduh untuk mendapatkan kenyataan. Sekiranya didapati bersalah, Pemeriksa Hal-hal Agama akan membuat laporan ke Pejabat Kadi daerah untuk tindakan penguatkuasaan oleh pihak Pejabat Kadi. ${ }^{37}$

\section{Sumbangan Pejabat Daerah dalam Meneutralkan Impak Pemodenan Johor}

Pada peringkat awal, tugas untuk memelihara dan memulihara agama Islam sewaktu era pemodenan tidak hanya dipikul oleh Jabatan Agama Islam semata-mata sebaliknya turut mendapat bantuan dan sokongan daripada beberapa agensi kerajaan lain di negeri Johor. 
Antara agensi kerajaan yang aktif membantu Jabatan Agama Islam ialah Pihak Berkuasa Tempatan. ${ }^{38}$ Dalam konteks ini, Pesuruhjaya Kerajaan memainkan peranan penting dalam membantu Jabatan Agama Islam. Ini dapat dilihat melalui bantuan Pesuruhjaya Kerajaan bagi daerah Mersing, Muar dan Segamat yang dapat meringankan bebanan tugas yang dipikul oleh Jabatan Agama Islam. Malahan, Mereka juga dilihat sangat prihatin terhadap perkembangan Islam di daerah yang ditadbir mereka. Contohnya, dalam usaha untuk mengimarahkan masjid sebagai tempat beribadat umat Islam, Pesuruhjaya Kerajaan bagi Daerah Segamat telah mengambil inisiatif untuk mengukuhkan sumber kewangan masjid-masjid dan surau-surau yang tidak mendapat bantuan daripada kerajaan. ${ }^{39}$ Oleh itu, Pejabat Daerah Segamat mengambil pendekatan untuk memberi kebenaran untuk masjid dan surau-surau yang tidak mendapat bantuan kewangan untuk mengusahakan tanahtanah yang telah dirampas dan tidak bertuan. Tujuannnya supaya hasil pendapatannya dapat digunakan sebagai dana untuk membiayai kos pengurusan dan pentadbiran masjid dan surau-surau tersebut. Berikut merupakan isi kandungan surat yang diberikan kepada Yang Dipertua Agama Islam:

Tiap-tiap kebun getah atau lainnya yang telah ditinggalkan dengan tiada bertuan atau telah jadi rampasan atau tertarik balik jadi hak kerajaan dengan sebarang jalan pada hal kebun itu ditinggalkan tiada siapa membela atau menerbitkan hasilnya jika ada hasil di mana-mana tempat yang lain dalam daerah ini patut diserahkan tanah kebun itu kepada suatu anggota yang menjaganya dan hasilnya dijadikan bantuan kepada masjid-masjid dan surau-surau di kampung atau tempat yang berhampiran dengan kebun tersebut. ${ }^{40}$

Perkara ini bertitik tolak daripada situasi masjid dan surau dalam daerah Segamat yang tidak terurus. Pada masa yang sama, langkah ini membolehkan pihak masjid menjalankan pelbagai aktiviti keagamaan seperti kelas agama, majlis berzanji dan membaca al-Quran.

Dalam konteks dakwah pula, Pesuruhjaya Kerajaan bagi Muar tampil dengan idea yang dilihat agak radikal tetapi relevan dengan situasi semasa. ${ }^{41}$ Pesuruhjaya Kerajaan bagi Muar pada tahun 1940 mengarahkan agar semua syarahan dan ceramah agama yang ingin dijalankan di Muar agar diadakan di Muar Club bukannya di masjid seperti kelazimannya. ${ }^{42}$

Sekali imbas tindakan ini dilihat sebagai menongkah arus. Walau bagaimanapun, langkah yang diambil oleh pihak Pesuruhjaya Kerajaan bagi Daerah Muar ini bertepatan dengan tujuan syarahan dan ceramah agama diadakan iaitu untuk memberikan kesedaran agama 
kepada masyarakat. Menurut Pesuruhjaya Kerajaan bagi daerah Muar pemilihan Muar Club yang menjadi tumpuan pelbagai bangsa bertujuan:
Saya percaya tujuan memberikan syarah-syarah itu ialah kepada orang-orang ramai lelaki dan perempuan dan khususnya kepada orang yang tiada mengerti dalam perkara atau ilmu agama dan lain- lainnya dan terlebih baik lagi pada faham saya ada bangsa-bangsa yang bukan Islam bersama-sama mendengarnya mudah-mudahan adalah perasaan yang mencenderungkan hati mereka itu masuk kepada agama Islam. ${ }^{43}$

Sekiranya dianalisis, langkah yang diambil oleh Pesuruhjaya Kerajaan bagi Muar adalah relevan dengan situasi pada ketika itu. Ini kerana, sekiranya syarahan dan ceramah agama diadakan di masjid, tentunya hadirin yang hadir terdiri dalam kalangan individu yang telah biasa hadir ke masjid dan individu yang mempunyai ilmu pengetahuan agama. Tambahan pula, tentunya kumpulan sasaran iaitu golongan yang tidak mengetahui ilmu agama tidak akan hadir kerana takut dan malu untuk menghadirkan diri ke masjid di atas kedangkalan ilmu agama mereka.

Tambahan pula, ruangan masjid juga terhad untuk menampung kapasiti hadirin yang hadir. Oleh yang demikian, langkah untuk mengadakan ceramah dan syarahan agama di Muar Club adalah tepat kerana Muar Club merupakan kawasan tumpuan orang ramai khususnya golongan muda serta mempunyai kawasan lapang yang luas. Selain itu, dengan bantuan pembesar suara, syarahan dan ceramah juga dapat didengari oleh penduduk kawasan yang berhampiran dengan Muar Club. Bagi menjayakan setiap syarahan dan ceramah agama yang ingin dijalankan di Muar Club, pihak Pesuruhjaya Kerajaan bagi Daerah Muar bersedia membantu teknikal menyediakan tempat untuk ceramah diadakan iaitu di padang Muar Club.

Selain itu, terdapat juga Pesuruhjaya Kerajaan yang rajin turun padang untuk bersemuka dengan masyarakat bagi menyelami masalah rakyat. Contohnya, Pesuruhjaya Kerajaan bagi Daerah Mersing dilihat kerap melakukan lawatan mengejut ke Sekolah-sekolah Agama Negeri Johor. ${ }^{44}$ Beliau dilihat sangat menitikberatkan soal pendidikan agama dalam kalangan penduduk Mersing. Malahan, beliau tidak berpuas hati terhadap perjalanan sekolah agama di Mersing setelah mendapati pengetahuan agama tenaga pengajar yang mengajar di Sekolah Agama Perempuan Mersing adalah amat cetek. Selain itu, sikap ringan tulang Pesuruhjaya Kerajaan Mersing ini berjaya mengesan gejala zina yang semakin mendarah daging dalam masyarakat Mersing. Oleh itu, beliau 
mencadangkan agar imam-imam dalam daerah Mersing diberi tauliah untuk menikahkan pasangan yang ingin berumahtangga. ${ }^{45}$

\section{Bantuan Pihak Polis dalam Aspek Penguatkuasaan Ajaran Islam di Johor}

Jabatan Agama Islam turut menerima bantuan daripada pihak polis dalam usaha untuk menguatkuasakan hukum Islam di Johor. Perkara ini adalah selaras dengan Undang-undang Polis Pos bilangan 5 tahun 1916 yang menetapkan bidang tugas polis “... kerja-kerja bagi polis pos ialah menjalankan segala peraturan dan syarat-syarat yang menurut undangundang bagi menegah dan mengakap dosa-dosa dan kesalahan" ${ }^{46}$ Fasal ini secara tidak langsung telah memberi kuasa kepada polis untuk menguatkuasakan Undang-undang Kesalahan Orang-orang Islam 1919.

Oleh itu, polis di Johor kerap kali membantu dalam menyampaikan saman terhadap individu yang melakukan kesalahan di sisi undangundang Islam. ${ }^{47}$ Ini kerana, dalam usaha menguatkuasakan Undangudang Islam, Jabatan Agama Islam turut berhadapan dengan pelbagai cabaran dan muslihat. Antara taktik yang digunakan adalah enggan menerima saman yang dikeluarkan oleh Kadi kepada mereka. Tindakan ini merupakan salah satu muslihat bagi mengelakkan diri daripada dihadapkan ke Mahkamah Kadi untuk perbicaraan.

Berdasarkan Aturan Menjalankan Bicara Mahkamah Syariah Di dalam Perkara yang Berkenaan Dengan Hal Ehwal Asyahsyisat menyatakan bahawa "...saman itu hendaklah sampai kepada yang kena saman dalam tempoh sebelum dua hari lain daripada hari terima dan datang mahkamah" ${ }^{48}$ Oleh yang demikian, terdapat segelintir pihak yang memanfaatkan kelemahan undang-undang ini untuk mengelakkan diri daripada dikenakan tindakan undang-undang. Perkara ini dapat dilihat dalam kes di Batu Pahat pada 1938 apabila penduduk kampung Layanglayang enggan menerima saman yang dikeluarkan oleh Pejabat Kadi atas kesalahan tidak membayar zakat fitrah. ${ }^{49}$ Kesannya mengakibatkan perbicaraan tidak dapat dijalankan ke atas mereka.

Oleh yang demikian, kerjasama pihak polis dalam menguatkuasakan Undang-undang Islam secara langsung mampu mengurangkan kes melanggar larangan agama serta menggalakkan orang ramai agar mematuhi undang-undang serta tidak mengambil remeh kewajipan dan larangan agama. ${ }^{50} \mathrm{Di}$ samping itu, pihak polis turut memberi maklumat mengenai sebarang perbuatan yang bercanggah dengan agama Islam. ${ }^{51}$ 


\section{Penghulu dan Imam sebagai Proksi untuk Memurnikan Ajaran Islam di Peringkat Akar Umbi}

Berdasarkan penelitian terhadap dasar-dasar pihak pemerintah Johor, sememangnya tidak dapat dinafikan bahawa kerajaan Johor begitu komited dalam usaha memelihara kedaulatan agama Islam. Persoalannya, bagaimanakah sambutan dan tindak balas daripada pihak bawahan terhadap usaha kerajaan? Oleh itu, bagi memastikan usaha-usaha kerajaan untuk memelihara agama Islam diterima oleh kumpulan sasaran, penghulu dan imam memainkan peranan penting sebagai proksi kepada Jabatan Agama Islam bagi memastikan ajaran Islam diaplikasikan dalam kehidupan seharian di peringkat kampung.

Dalam konteks ini, penghulu menjadi jambatan perhubungan antara rakyat dengan pemerintah. Oleh itu, penghulu diamanahkan untuk mengindoktrinasikan ajaran Islam di peringkat akar umbi. Sehubungan itu, penghulu-penghulu di seluruh Johor diwajibkan untuk memberi syarahan agama selepas solat Jumaat. ${ }^{52}$ Perkara ini diselaraskan di bawah Fasal 2 Buku Panduan Penghulu yang menggariskan kewajipan penghulu dalam perkara agama iaitu:

Hendaklah tiap-tiap penghulu mengerjakan sembahyang dan puasa dan mendirikan Jumaat jikalau cukup bilangan orang dan sembahyang dua hari raya dan mengerjakan barang yang wajib atas sekalian orang Islam dan menjauhkan segala larangan ... menyuruh anak-anak buahnya yang beragama Islam mengerjakan suruhan Allah dan menjauhkan segala larangan.

Langkah ini bertepatan dengan kedudukan penghulu yang rapat dengan masyarakat sekali gus membolehkannya mengetahui situasi dan masalah sebenar dalam masyarakat di mukimnya. Cara ini merupakan satu platform bagi penghulu untuk menasihati penduduk kampung dalam soal agama. Memandangkan pentingnya ilmu agama dalam era pemodenan Johor, maka imam-imam ditugaskan untuk mengajar agama kepada penduduk kampung. ${ }^{53}$ Kebiasaannya, imam akan mengadakan kuliah agama di Masjid selepas solat Maghrib pada malam Jumaat dan pada petang Jumaat bersesuaian dengan peranan institusi masjid sebagai pusat penyebaran ilmu. ${ }^{54}$ Peranan imam tidak hanya terhad di peringkat kampung sahaja kerana terdapat segelintir imam yang ditugaskan untuk mengajar agama di hospital dan penjara. ${ }^{55}$ Situasi ini menggambarkan bahawa agama Islam tidak pernah diabaikan dalam keghairahan kerajaan mengejar pemodenan. Sebaliknya agama Islam dijaga rapi oleh pihak pemerintah sehingga ke peringkat akar umbi dengan kerjasama penghulu dan juga imam. 


\section{Kesimpulan}

Secara keseluruhannya, Jabatan Agama Islam dilihat berperanan sebagai tulang belakang dalam meneutralkan kesan negatif yang timbul akibat daripada proses pemodenan. Dalam konteks ini Jabatan Agama Islam berperanan sebagai "arkitek" yang merangka pelan untuk memelihara dan memulihara agama Islam di negeri Johor serta pada masa yang sama turut memantau perkembangan agama Islam di negeri Johor.

Dalam usaha untuk memelihara dan memulihara agama Islam, Jabatan Agama Islam telah membawa masuk serta mengaplikasikan nilai-nilai dan idea-idea Islam yang moden dari negara-negara Arab. Perkara yang berlaku secara langsung membuktikan bahawa agama Islam tidak disisihkan sewaktu proses pemodenan malahan bergerak selari dengan arus pemodenan. Perlu ditegaskan dalam perbincangan ini bahawa tugas memelihara dan memulihara agama Islam di negeri Johor tidak hanya bergantung kepada Jabatan Agama Islam dan agensi pelaksana di bawahnya semata-mata. Sebaliknya beberapa agensi kerajaan di negeri Johor seperti Pejabat Daerah, Pihak Polis serta Penghulu dan Imam telah tampil dengan inisiatif yang tersendiri untuk turut serta berganding bahu dalam usaha memelihara dan memulihara agama Islam di negeri Johor.

\section{Nota}

1 Abd Latif Juffri @ Al-Jufri \& Jainal Sakban Al-Jauhari, Sejarah Perkembangan Agama Islam Johor, Johor: MAIJ URUS Sdn Bhd, 2008, hlm. 40.

2 Rahimah Abdul Aziz, Pembaratan Pemerintahan Johor (1800-1945): Suatu Analisis Sosiologi Sejarah, Kuala Lumpur: Dewan Bahasa dan Pustaka, 1997, hlm. 108.

3 J/UG 1, Penyata Jabatan Agama Johor 1938, Arkib Negara Johor.

$4 \quad$ Pada 1862, bertitik tolak daripada kontroversi hukuman denda yang dijatuhkan kepada sekumpulan nelayan Cina yang didapati bersalah berjudi di negeri Johor. Maharaja Abu Bakar terpaksa tunduk kepada tekanan British dengan melaksanakan penyemakan semula Johor sekali gus melahirkan "Kod Jenayah Johor".

5 J/UG X, Majalah Ahkam Johor, Arkib Negara Johor.

6 Ibid., hlm. 7.

7 Empayar Turki Uthmaniyah merupakan pusat pemerintahan institusi khalifah Islam dan menjadi rujukan Johor dalam hal-ehwal agama pada ketika itu. Lihat Abd. Jalil Borham, Majalah Ahkam Johor Latar Belakang, Pelaksanaan dan Komentar, Skudai: Penerbit Universiti Teknologi Malaysia, 2002, hlm. 46.

8 Abd. Jalil Borham, 'Jati Diri Johor Dari Aspek Agama: Kesungguhan Johor Melaksanakan undang-undang Islam dengan Pelaksanaan Majalah Ahkam Johor', Dalam Ismail Adnan \& Rafie Abdul Rahim, Jati Diri Johor 
Dalam Pelbagai Perspektif (Himpunan Kertas Kerja Seminar Jati Diri Johor), Johor: Yayasan Warisan Johor, 2008, hlm. 103.

Jabatan Agama Islam juga sentiasa mengimport majalah dan kitab-kitab agama khususnya daripada Mesir untuk memperkayakan pengetahuan mengenai agama Islam. Lihat J/UG 7 225/38, Memohon Majalah Al-Islam dan Satu Majalah Harian Mesir yang Tetap Kerana Supaya Mengetahui Perkara-perkara yang Berkenaan Dengan Fatwa-Fatwa Hukum Islam. Lihat juga J/UG 7 667/37, Meminta Undang-undang dan Peraturan Mahkamah Syariah dan Baitulmal Mesir.

J/UG 7 2/37, Bawah DYMM telah Berkenan Datuk Yang Dipertua Agama Pergi ke Mekah Bagi Menghajikan Allahyarhamah Cik Besar Zubaidah Kemudiannya Dititahkan Ziarah ke Mesir Melihat Aturan-aturan Di dalam Jamik il Azhar Selama Enam Bulan dan Membawa Seorang Kawan Syed Harun bin Muhd Fadhil. Lihat juga JMB 1/37, Ke bawah DYMM Berkenan Datuk Yang Dipertua Agama pergi ke Mekah Bagi Menghajikan Allahyarhamah Cik Besar Zubaidah Kemudiannya Dititahkan Ziarah ke Mesir Melihat Aturan-aturan Di dalam Jamik il Azhar Selama Enam Bulan dan Membawa Seorang Kawan Syed Harun bin Muhd Fadhil, Arkib Negara Johor.

"Penal Code" diletakkan di bawah Kod Jenayah dan diimplementasikan di negeri-negeri Selat sebagai garis panduan sistem perundangan di negeri Johor. Untuk keterangan lanjut sila lihat R.O Winstedt, A History of Johor 1365-1895, Kuala Lumpur: Art Printings Work, 1979, hlm. 96.

Sebelum 1910, sistem perundangan di negeri Johor menggunakan Kod Jenayah Johor yang telah disesuaikan dengan sistem perundangan Islam seperti yang diterangkan di dalam Hikayat Johor sebagai garis panduan dan rujukan dalam menjatuhkan hukuman. Walau bagaimanapun, berpunca daripada kontroversi tindakan kerajaan Johor menjatuhkan hukuman denda terhadap sekumpulan Cina dari Singapura yang didapati bersalah kerana berjudi pada Jun 1861, polemik ini terus membara sehingga menjadi "duri dalam daging" dalam konteks hubungan diplomatik antara Johor dengan kerajaan Negeri Selat di Singapura. Gabenor Cavenagh telah mengkritik sistem perundangan Johor yang dianggap sebagai "primitif" dan tidak bertamadun sekiranya dibandingkan dengan undang-undang Inggeris. Oleh yang demikian, kerajaan Johor telah mengambil inisiatif untuk mengaplikasikan sistem perundangan Barat iaitu merujuk kepada Panel Code dan Civil Code seperti yang dilaksanakan oleh pentadbiran British di Singapura.

J/PU 1, Enakmen Kesalahan-kesalahan Orang-orang Islam, Bilangan 25 Tahun 1919.

$14 \quad$ Undang-undang ini sebenarnya kesinambungan undang-undang bilangan 9 tahun 1914 yang telah dikemas kini dan diberi nafas baru. Untuk maklumat lanjut sila lihat J/SUK 1 SS 732/1919, Mengenai Cadangan Merangka Undang-undang Bagi Mengawal Masalah Perempuan/ Perawan Sundal. J/SUK 10, Johore Government Gazette 1919, Enactment No. 25 of 1919. 
16 General Adviser 369/1936, Prostitution in Johore. Lihat juga JUG 7 541/1939, Menyatakan Keputusan Perbicaraan Undang-undang Kesalahan Orang-orang Islam di Batu Pahat.

17 J/SUK 10, Johore Government Gazette 1919, Enactment No. 27/1919.

18 Dalam Undang-undang Bilangan 27 Tahun 1919, sebarang polemik yang timbul dalam melaksanakan Undang-undang Kesalahan-kesalahan Orangorang 1919 haruslah dirujuk kepada Mufti kerajaan Johor dalam bentuk surat. Dalam konteks ini, Mufti diberikan tempoh tiga puluh hari untuk mengeluarkan fatwa bagi menjawab permasalahan yang timbul. Untuk maklumat lanjut sila lihat J/PU 1, Undang-undang Bilangan 27 Tahun 1919. Lihat juga J/SUK 1, Johore Government Gazette, Enactment No. 27 of 1919.

19 Saudara-saudara baru akan diajarkan ilmu asas agama dan fardu ain seperti yang dapat dilihat dalam laporan harian Lebai Hussin iaitu seorang guru agama yang ditugaskan untuk mengajar orang Jakun yang baru memeluk Islam. Antara perkara yang diajar oleh beliau ialah cara menunaikan solat, berpuasa, mandi wajib dan asas-asas tauhid iaitu mengenai Allah. Untuk Keterangan lanjut sila lihat J/UG 7540/36, Lebai Husin Mengajar Agama di Hulu Pagoh dan Mengislamkan Orang-orang Jakun Di tempat Tersebut dan Mohon Bercuti.

Perihal Mufti Johor yang mengambil inisiatif untuk mengambil seorang mualaf untuk bekerja dengannya. Untuk keterangan lanjut sila lihat J/ UG 7 714/40, Mengadakan Syarahan Agama Merata-rata Kampung Di dalam Wilayah Johor Dikehendaki Mufti Kerajaan Anggaran Belanjabelanjanya Sebanyak \$2050 Termasuk Membeli Sebuah Motokar Ford, Loud Speaker dan Mengaji Seorang Dikeluarkan Dari Bahagian Mualaf Tahun ini Sebagaimana Suratnya. J/UG 1, Penyata Tahunan Jabatan Agama Islam 1936. Lihat juga J/ UG 2, Penyata Zakat Johor Tahun 1939. Singapore and Straits Directory, 1896, hlm. 277. Lihat juga Ahmad Fawzi Basri dan Hasrom Haron, Sejarah Johor Moden 1855-1940, hlm. 176.

$23 \quad$ Ibid., hlm.176.

24 J/UG 1, Penyata Jabatan Agama Johor 1935.

25 J/UG 7 (Mufti Johor) 195/38, Perihal di Johor Bahru.

26 Dalam usaha mengatasi masalah ajaran sesat, Undang-undang Kesalahankesalahan Orang-orang Islam 1919 mensyaratkan setiap individu yang ingin mengajar agama kepada orang awam perlulah mendapat tauliah daripada Jabatan Agama Islam. Bagi mendapatkan tauliah, ilmu agama individu tersebut akan diperiksa terlebih dahulu. Lihat J/PU 1, Enakmen Kesalahan-kesalahan Orang-orang Islam, Bilangan 25 Tahun 1919. Lihat juga Abd Latif Juffri @ Al-Jufri \& Jainal Sakban Al-Jauhari, Sejarah Perkembangan agama Islam Johor, hlm. 35.

J/UG 7 714/40, Mengadakan syarahan agama merata-rata kampung di dalam wilayah Johor. Lihat juga J /UG 7 644/39, Habib Mufti Bersyarah di Masjid Jamik Muar Pada Hari Rabu Pukul 2.30 Petang Pada 27.12.1939 Bersama Yang Berhormat Datuk Yang Dipertua Agama. 
J/UG 7 286/39, Peraturan Mahkamah Kadi, Pemeriksa Perkara Agama Mengandungi Kes-kes Jumaat dan Mengambil Dari Buku Jumaat Merepotkan Kepada Kadi dan Dikeluarkan Saman dan Didakwa. Lihat Juga J/UG 7 67/35, Tidak Menyain dalam Buku Jumaat.

J/UG 7 244/28, Report Tahunan Pejabat Agama 1928. Lihat Juga J/UG 7 313/28, Pohon Copkan Seribu Naskhah Menegah Jual Beli Pada Hari Jumaat Kepada Orang Islam dalam Masa Diserukan Sembahyang Jumaat. Tiada satu skim atau pekeliling yang dikeluarkan oleh Pejabat Agama dan Pejabat Kadi Besar mengenai pinjaman wang baitulmal kepada kakitangan kerajaan untuk mendirikan perkahwinan. Namun, terdapat resit-resit pemberian pinjaman kepada kakitangan kerajaan berdasarkan penelitian terhadap fail Pejabat Agama. Lihat J/UG 7 580/40, \$80 Pinjaman Kahwin kepada Abdul Wahid Warden Special Gred. Lihat juga J/UG 7 607/40, Munaji Bin Haji Abdul Rahman Operator Telefon Memohon Pinjaman Kerana Kahwin Sebanyak \$84.

31 Perlu ditegaskan dalam perbincangan ini bahawa Pemeriksa Hal Ehwal Agama bukan sahaja terletak di bawah kawalan Yang Dipertua Agama semata-mata, tetapi turut bertanggungjawab kepada Mufti dan Kadi Besar Johor. Oleh itu, adalah tidak menghairankan jika terdapat arahan-arahan yang dikeluarkan oleh Mufti dan Kadi Besar kepada Pemeriksa Hal-hal Agama dalam usaha memelihara dan memulihara agama Islam di Johor. J/UG 7 238/38, Pemeriksa Hal-hal Agama di Johor, Muar dan Batu Pahat Diperintahkan Menyiasat Tiap-tiap Tempat dan Kampung Serta Merepotkan Tiap-tiap Bulan Atas Perjalanan Kerjanya Betul-betul Telah Disempurnakan. J/UG 7 270/38, Penyata Perjalanan Pemeriksa Hal-hal Agama Johor (Haji Ahmad bin Omar).

34 Penyata Pemeriksa Hal-hal Agama mengandungi segala tugas yang dilaksanakan oleh Pemeriksa Hal-hal Agama serta perkembangan agama di kawasan-kawasan yang dilawati olehnya. Contohnya Pemeriksa Hahal agama bagi daerah Batu Pahat mencatatkan kegiatan agama di bulan Ramadan bahawa selepas berbuka puasa beliau menunaikan sembahyang Maghrib secara berjemaah di masjid dan kemudiannya memberi syarahan agama sementara menunggu masuk waktu Isyak. Kemudiannya beliau bersama-sama jemaah menunaikan solat Isyak dan Terawih dan dilanjutkan dengan program membaca Al-Quran sehingga pukul 12 tengah malam. Dalam laporannya juga pemeriksa agama memberikan anggaran jumlah jemaah yang hadir ke masjid, masa dan tempat serta aktiviti-aktiviti keagamaan yang dijalankan di sesuatu kawasan untuk memberi gambaran tentang perkembangan agama Islam kepada Yang Dipertua Agama. Lihat J/UG 7 270/38, Penyata Perjalanan Pemeriksa Hal-Hal Agama Daerah Batu Pahat Bagi Tiap-tiap Bulan Bagi Tahun 1939. J/UG 7 270/38, Penyata Perjalanan Pemeriksa Hal-hal Agama Johor (Haji Ahmad bin Omar). Ibid.

37 Perlu ditegaskan dalam perbincangan ini bahawa Pemeriksa Hal-hal Agama tidak mempunyai autoriti untuk mengambil tindakan undang- 
undang terhadap individu-individu yang melakukan kesalahan. Bidang tugasnya hanyalah berkisar aktiviti menjalankan siasatan dan pemantauan terhadap agama Islam. Kuasa untuk mengeluarkan saman terletak di tangan Kadi, Naib Kadi dan Penolong Naib Kadi sahaja.

Pihak Berkuasa Tempatan ini diterajui oleh Pesuruhjaya Kerajaan. Jawatan Pesuruhjaya Kerajaan ini ditubuhkan untuk menyelia hal-hal pentadbiran, pertahanan, keadilan dan kewangan peringkat daerah selaras dengan sistem pentadbiran Barat yang acuan sistem pentadbiran Johor sewaktu proses pemodenan. Pada dasarnya, bidang agama adalah di luar bidang tugas Pesuruhjaya Kerajaan. Namun, secara praktiknya Pesuruhjaya kerajaan memainkan peranan sebagai pemerhati agama yang banyak membantu dari aspek khidmat nasihat dan teknikal.

Masjid dan surau yang tidak mendapat bantuan kerajaan merupakan masjid dan surau yang dibina atas inisiatif penduduk kampung dengan menggunakan perbelanjaan sendiri.

J/UG 7 518/3, Masjid-masjid yang Ada Mendirikan Jumaat di Wilayah Segamat dalam Peliharaan Penduduk Kampung Tidak Begitu Baik Kerana Kekurangan Belanjanya. Berdasarkan dokumen ini, telah disyorkan bahawa setiap kebun yang ditarik balik atau dirampas oleh kerajaan akan diserahkan kepada suatu anggota masyarakat yang boleh menjaganya supaya dapat memberi bantuan kepada masjid.

Berdasarkan surat-surat yang dikirimkan oleh Pesuruhjaya Kerajaan bagi Daerah Muar kepada Yang Dipertua Agama Islam Johor menggambarkan pemikirannya yang berpandangan jauh. Malahan beliau sangat prihatin terhadap golongan muda. Contohnya beliau pernah melahirkan kebimbangannya mengenai gejala lepak dalam kalangan golongan muda di Bandar Maharani yang berpotensi untuk menyumbang kepada peningkatan masalah sosial di Muar. Malahan beliau sendiri mengambil inisiatif untuk turun padang memeriksa pengetahuan ilmu agama pemuda-pemuda tersebut dan didapati majoritinya jahil dalam bidang agama. Oleh itu, beliau meminta Penolong Kadi Muar agar mengarahkan seorang guru agama untuk menarik golongan muda tersebut untuk ke masjid dan mempelajari ilmu agama. Lihat J/UG 7 441/40, Budak-budak Muda yang Telah Cukup Umur Ia Telah Melihat Banyak Benar yang Duduk Bersepah Di merata-merata Simpang Jalan dan Di kedai Kopi Dalam Kawasan dan Di Luar Kawasan Bandar Maharani.

Muar Club merupakan rumah rehat yang dibina di bandar Muar yang menjadi tumpuan orang ramai khususnya golongan muda kerana menyajikan aktiviti-aktiviti hiburan.

43 J/UG 7 315/40, Mengesyorkan Tiap-tiap Kali Syarah Supaya Diadakan Di Muar Club Tidak Di Masjid Jamik Iaitu Supaya Rata-rata Lelaki dan Perempuan Dapat Mendengarnya dan Dipohonkan Dapat Dibeli Satu Pembesar Suara Dengan Harga \$350 Dibayar Dari Wang Amanah Zakat Bagaimana Suratnya.

44 Pesuruhjaya Kerajaan bagi Daerah Mersing juga menyarankan agar Penolong-penolong Kadi Besar di peringkat daerah agar memantau proses pembelajaran dan pengajaran Sekolah-sekolah Agama di daerah 
masing-masing. Lihat J/KAD 2 7/34, Penolong Kadi Besar Dikehendaki Melawat Sekolah-sekolah Agama Lelaki dan Perempuan Tiap-tiap Tiga Bulan Bekali.

Pesuruhjaya Kerajaan bagi Daerah Mersing berpendapat bahawa peningkatan masalah zina dalam kalangan masyarakat Mersing adalah berpunca daripada kesukaran untuk menjalankan proses perkahwinan. Hal ini dikaitkan dengan bentuk muka bumi Mersing yang berpulaupulau sehingga menyukarkan Naib Penolong Kadi untuk datang bagi menikahkan pasangan yang ingin berkahwin. Lihat J/UG 7 412/37, Mengesyorkan Moleklah Imam yang Ada Di Pulau-pulau Daerah Mersing Itu Diberi Kepadanya Tauliah Boleh Menikahkan Orang-orang Kampungnya Kerana Banyak Benar Telah Berlaku Perkara-perkara Zina Anak-anak Kampung Oleh Kekurangan Juru nikah. J/PU 1, Undang-undang Polis Pos Bilangan 5 bagi tahun 1916. Pihak polis juga akan mengambil butir peribadi individu yang didapati melanggar hukum Islam seperti melakukan maksiat dan tidak berpuasa di bulan Ramadan. J/UG 2, Aturan Menjalankan Bicara Mahkamah Syariah di dalam Perkara yang Berkenaan Dengan Hal Ehwal Asyahsyisat.

Pada hemat mereka, pihak Pejabat Kadi tidak akan dapat mengambil tindakan undang-undang terhadap mereka tanpa waran dan surat saman. Oleh itu, mereka mengambil inisiatif untuk tidak menerima surat saman bagi mengelakkan tindakan undang-undang. Lihat J/UG 7 341/38, Merepotkan Mengenai Keengganan Beberapa Orang Kampung Enggan Menerima Saman Tidak Membayar Zakat. J/UG 7 562/ 36, Menyatakan Pesuruhjaya Polis Bersetuju Pihak Polis Boleh Menyampaikan Saman-saman Mahkamah Kadi Terutamanya Di tempat yang Jauh-jauh.

51 Assistant Commissioner Polis Johor melaporkan kepada Jabatan Agama Islam bahawa pihak polis mendapat maklumat daripada orang awam bahawa penduduk di Kampung Batu 4 1/2, Skudai, Johor berubat dengan "menurun" hantu. Tindakan mereka itu bercanggah dengan pekeliling yang dikeluarkan oleh Jabatan Agama Islam yang melarang orang Islam di Johor memasang ancak menyediakan korban untuk makhluk halus yang bertentangan dengan syariat Islam serta merosakkan akidah. Ini memperlihatkan bahawa pihak polis sentiasa cakna terhadap pekeliling yang dikeluarkan oleh Jabatan Agama Islam. Lihat J/UG 7 529/40, Berubat Dengan Berhantu Orang-orang Kampung Jalan Batu 4 1/2 Jalan Skudai Menyalahi Dari Pekeliling Jabatan Agama.

JMB 398/39, Minta Penghulu Sampaikan Syarah Agama Selepas Sembahyang Jumaat.

53 Terdapat banyak kelas-kelas agama yang dijalankan di peringkat bawahan untuk menambah pengetahuan agama. Kelas-kelas ini dibiayai oleh wang kutipan zakat. Untuk keterangan lanjut sila lihat J/ UG 2, Penyata Zakat Johor Tahun 1939. Lihat Juga J/UG 1, Penyata Jabatan Agama Johor Bagi Tahun 1939. Lihat juga J/UG 7 296/40, Elaun Mengajar Agama Dari Wang Zakat Bagi Tahun 1940 Kepada Daerah. 
54 Pejabat Agama Islam Johor mengeluarkan pekeliling kepada sesiapa yang ingin mempelajari ilmu agama supaya hadir ke masjid kerajaan dan masjid-masjid di kampung tiap-tiap seminggu sekali iaitu pada malam Jumaat lepas maghrib bagi kaum lelaki dan pada hari Jumaat pukul 4 hingga 5 petang untuk kaum perempuan. Lihat J/UG 7 763/40, Pemberitahuan Kepada Sekalian Orang Islam lelaki dan Perempuan Sesiapa Sahaja yang Hendak Tahu dan Wajib Mengetahui Pekerjaanpekerjaan Agama Fardu. Lihat juga J/KAD 2 17/35, Menguatkan Imamimam Jumaat dan Imam Surau Supaya Mengajar Orang Kampung Berkenaan Agama Dengan Kuat.

55 J/KAD 2 214/34, Melawat Ke Hospital Kerajaan. Lihat juga 468/40, Dikehendaki Bil Tuntutan Imam-imam yang Pergi Ke Hospital Kerana Mengajar Orang Sakit Hendak Dikembarkan Dengan Satu Penyata Apa-apa yang Diajarnya dan Apa yang Ada Orang Sakit dan Berapa Banyaknya. 